\title{
\Ј
}

\section{Fecha os olhos e vê!}

Elisa de Magalhães

Universidade Federal do Rio de Janeiro edemagalhaes@gmail.com

Desde que acordamos, piscamos os olhos o dia todo. Nem percebemos, mas, sem esse gesto simples, a piscadela, não podemos ver. Ela serve para conservar a mucosa da superfície ocular úmida. O que vemos ocorre em intervalos rítmicos entre as piscadas, isto é, simplesmente, entrevemos. Sem sequer percebermos que piscamos, embora saibamos disso.

Cegueiras em intervalos de visão ou visão em intervalos de cegueiras: assim vemos, argumenta Jacques Derrida em seu livro Memórias de cego e outras ruínas (Derrida, 2010). Ver, portanto, obedece à lei da entrevista: o que vemos é o entre, e a cegueira é parte da experiência do ver. Nesse mesmo livro, Derrida diz que a experiência é como viajar além do limite e, ao mesmo tempo, reconhecendo e criando novos limites. Decorre daí que ver é reconhecer, mas é também conhecer.

Sendo assim, penso que ver é ir além dos limites reconhecíveis, como uma espécie de jogo de devir memória. Mas quanto de memória há no ver imediato? Há memória no ver imediato?

Fecha os olhos e vê, diz James Joyce em Ulisses.

Inelutável modalidade do visível: pelo menos isso se não mais, pensado através dos meus olhos. [...] Limites do diáfano. Mas êle acrescenta: nos corpos. Então êle se compenetrava dêles, corpos antes deles coloridos. Como? Batendo em sua cachola contra eles, com os diabos. Devagar. Calvo êle era e milionário, maestro di color che sanno. Limite do diáfano em. Por quê em? Diáfano, adiáfano. Se se pode pôr os cinco dedos através, é porque é uma grade, se não uma porta. Fecha os olhos e vê. (Joyce, 1966, p. 41-42).

Pensado através dos olhos, no ritmo entre o diáfano e o adiáfano, compenetrado para ver os corpos antes. O ver parece implicar em reconhecer no entre. Mas vemos ou pensamos que vemos? Penso que as duas considerações estão na ação do ver, porque o ver implica também não ver. Em algum momento, entre as piscadelas, o ver é memória do que acabamos de olhar. 
O paradigma platônico da caverna (Ginsburg, 2014, p. 223-261) para o ver, de alguma maneira, enceguece e limita nosso pensar sobre isso. Ali, a lucidez e o esclarecimento eram o fim e o objetivo da experiência espeleológica. No entanto, aceitando a ideia platônica, fechamos os olhos à cegueira que é própria da experiência do ver.

Se tomamos a definição derridiana de experiência, temos que para ver não basta estar na luz, mas é preciso reconhecer os limites nas entrevistas permitidas pelas piscadelas, entre os momentos de cegueira. Embora de certa maneira limitante, gosto da definição de Robert Morris de presentidade.

O artista acreditava numa mudança na percepção do tempo. Assim, os artistas-escultores de sua geração experimentavam o tempo como duração, diferentemente dos artistas-escultores do início do século. Para ele, a condição da escultura minimalista era a da experiência espacial, na medida em que a percepção do espaço estava impregnada na própria natureza da obra. E ia além: essa percepção funcionava como uma espécie de "espaço mental", análogo ao mundo, mas sem localização no interior do corpo; todavia, seria esse espaço virtual, sem lugar dentro ou fora do corpo, o responsável pela consciência.

O artista baseava-se na pesquisa do psicólogo norte-americano Julian Jaynes ${ }^{1}$, que sugere ter a consciência subjetiva se desenvolvido na medida do desenvolvimento linguístico do ser humano. Morris diferenciava dois modos de percepção do espaço, que estão sempre relacionados na experiência espacial de qualquer natureza: a imediata e a memória. Esta está sempre ligada à imaginação, à fantasia, à reflexão, que é completamente diversa da experiência imediata. O cenário da memória é de imagens estáticas, como stills do tempo - aí identifico a limitação na definição de presentidade de Morris, isto é, a imagem estática, a fotografia como "isso foi", como a captura de um momento por uma única imagem, como se a memória fosse fragmento, ruína, mas de um passado perfeito.

Ora, a memória é dinâmica, fluida, tão fílmica em sua percepção como a experiência imediata. Porque ela é ruína na origem, não há um passado perfeitamente construído do qual ela é parte, única, estática - ao passo que a experiência ime-

1 Julian Jaynes (1920 - 1997) - Psicólogo norte-americano em cujo principal livro, The Origin of Conscienciousness in the Breakdown of the Bicameral Mind", desenvolve a teoria de que, antes da linguagem, o ser humano não tinha consciência. Julian defende que é resultado do desenvolvimento linguístico do ser humano. 
diata acontece no movimento. A percepção espacial é sempre a relação entre os dois modos de perceber o espaço (ou, como preferia Morris, a oposição binária desses modos de percepção), isto é, o fluxo do experimentado e a estaticidade do lembrado no processamento de imagens. É uma operação dupla, como o self. "A apresentação de si [self] para si mesmo, uma operação mais complexa envolvendo tanto o uso extensivo da linguagem quanto o da imaginação (Ferreira; Cotrim, 2006, p. 403).

Morris também toma emprestado do filósofo norte-americano George Herbert Mead $^{2}$ a divisão do self em eu e mim, sendo o eu o self experimentado no tempo presente, e o mim o self reconstituído por indícios relembrados, portanto, fazendo parte da memória e da imaginação. Eu e mim nunca podem coexistir com a experiência imediata, mas se acompanham em partículas, pedaços. A ideia de presentidade está intimamente ligada a esta divisão de self, na medida em que, para Morris, ela é a inseparabilidade íntima da experiência do espaço físico e daquela de um presente continuamente imediato.

Sendo assim, se o real só pode ser experimentado em tempo real, então o corpo em movimento altera a percepção, na medida que altera os pontos de vista no vértice do tempo, como se fosse uma alteração de foco - a linguagem, a memória, a fantasia e a reflexão não acompanham a experiência imediata do espaço, porque ela só acontece no tempo real, imediato, no aqui-agora. No entanto, as alterações de foco evocam como memória a experiência espacial que acabou de ser vivida.

Morris, portanto, relaciona os dois tipos de self - eu e mim - aos dois tipos de percepção espacial, sendo o eu a percepção do espaço no presente contínuo, imediato - vivência do espaço no movimento. E o mim, sendo o constituinte retrospectivo, o vivido, a memória do que já passou ou acabou de passar. Mim sempre estabelece um paralelo com o eu, na percepção espacial, mas jamais se encontram. O artista leva essa ideia para a apreensão de objetos no espaço, porque a apreensão do objeto é memória e tempo presente, ao mesmo tempo: o objeto é estático, como a imagem da memória, independente do que está em torno.

2 George Herbert Mead (1863 - 1931) - Filósofo americano que, junto com William James, Charles Pierce e Johnn Dewey faz parte da corrente teórica da filosofia americana, chamada de Pragmatismo. 
E ele vai além quando afirma que a percepção do espaço é uma experiência tipo eu, transmutada para o domínio do mim, na medida em que a memória é o elemento operativo. Ele justifica recorrendo a Roland Barthes, falando sobre o ato de escrever sobre o self:

Eu mesmo sou meu próprio símbolo, sou a história que acontece comigo: andando livremente na linguagem, não tenho nada com que me comparar e, nesse movimento o pronome do imaginário 'eu' é im-pertinente; o simbólico se torna literalmente imediato..." (Barthes apud Ferreira et al., 2006, p. 405).

Exigindo movimento físico e duração, a experiência espacial interpõe uma extensão entre as duas modalidades - eu e mim. A dimensão do tempo evita a coincidência entre elas. $\mathrm{E}$ a consciência da experiência artística termina na modalidade mim.

O espaço mental, para Morris, é um lugar que não existe como espaço físico, real; esse lugar sem profundidade pode estar representado num objeto, que carrega nele, portanto o eu e o mim, sua construção e desconstrução, o tempo presente e a memória, na medida em que os aspectos da percepção mudam no tempo, de acordo com o ponto de vista do espectador.

A relação do espectador com a obra já é, portanto, ruína na origem, por causa da presentidade - ela é memória e é o tempo imediato ${ }^{3}$. Uma relação que acumula tempos diferentes, ou de naturezas diferentes, e que correm paralelos, sem jamais se tocarem. Sua coincidência é estarem no objeto, um e outro, indecidível.

A presentidade de Morris é uma experiência comportamental e temporal ao mesmo tempo, e não de natureza gestáltica, no olho, instantânea. As obras de arte operam a coexistência do trabalho e do espaço do observador, a possibilidade das múltiplas vistas, a utilização de distâncias e espaços profundos, que destacam a importância do tempo e da suposição de aspectos subjetivos da percepção. Para o artista, essas são características que deslocam os trabalhos de arte para uma sensibilidade e experiência barrocas, sem acompanhar, no entanto, o tipo de imagem do Barroco: os trabalhos que trazem a presentidade como experiência consciente, isto é, o primeiro acesso à experiência espacial, que é sempre do tipo eu, é imedia-

3 Embora não caiba aqui, é interessante lembrar a hipótese freudiana do bahnung como representação da memória, que Jacques Derrida desenvolve no texto "Freud e a Cena da Escritura", compilado no livro DERRIDA, Jacques. A escritura e a diferença. Tradução Maria Beatriz Marques Nizza da Silva. São Paulo: Perspectiva, 2005. 
tamente convertido na esquematização da memória - percepção tipo mim. Nesse sentido, a experiência da obra antecede as imagens da memória. $E$, no entanto, não se pode separar as experiências/percepções do tipo eu e do tipo mim, elas não se encostam, mas acontecem concomitantemente, imagem e tempo, paralelamente, eu e mim; no momento mesmo de seu acontecimento já é imagem arruinada, memória, mas pleno de imaginação ou restos, marcas, espectros.

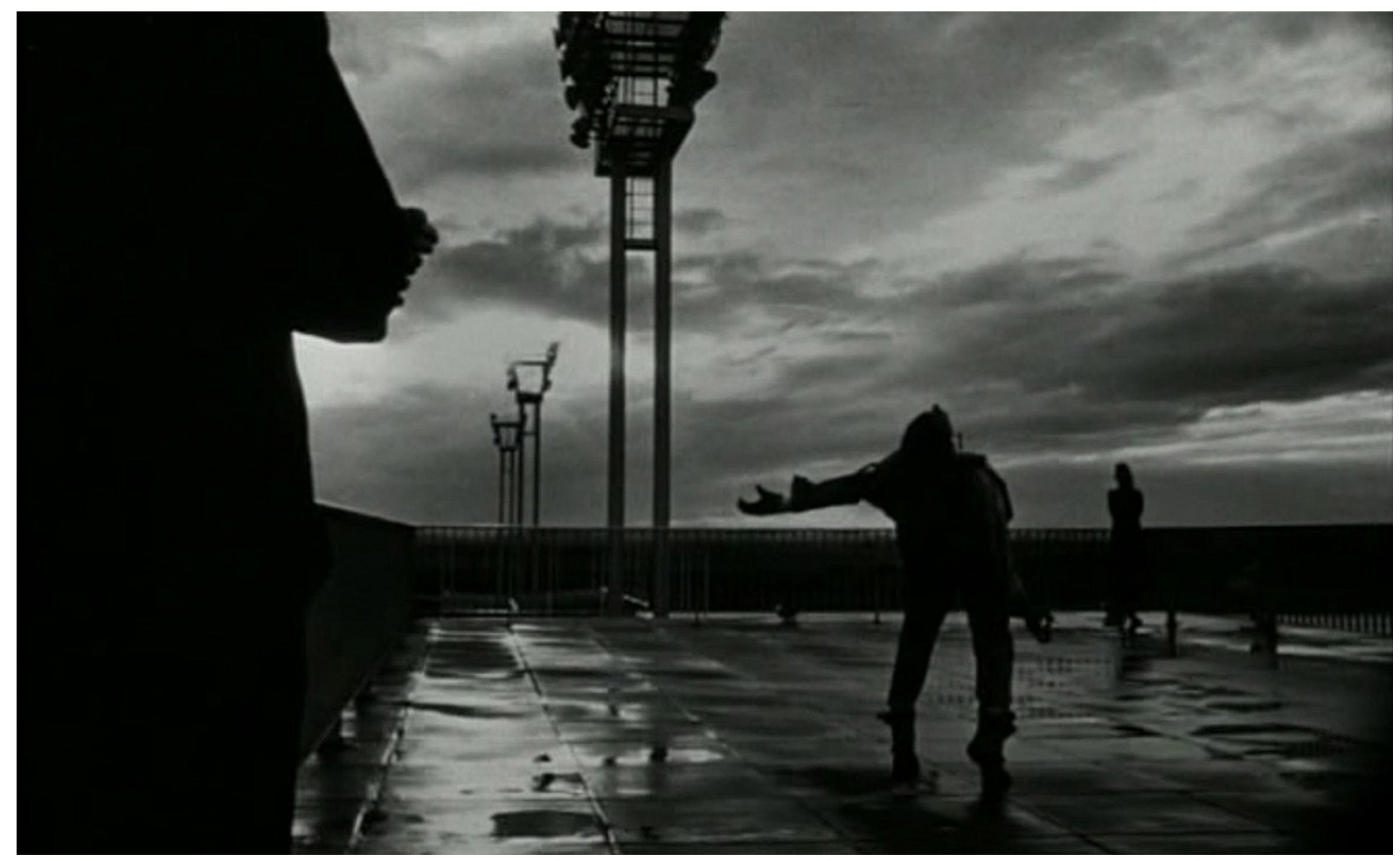

Figura 1. Fotograma do filme La Jetée, de Chris Marker (1962)

O filme La Jetée (A Plataforma), do cineasta Chris Marker, feito em 1962, fricciona ao máximo a questão contida na presentidade - a de memória como imagens estáticas -, além de levantar uma hipótese: a de que a fotografia sempre conteve nela o cinema, mesmo quando ele ainda não tinha sido inventado. Afinal, um filme é uma sucessão de fragmentos, os fotogramas, isto é, são imagens estáticas que, projetadas em sequência, nos dão a ideia de movimento.

La Jetée é um filme de ficção científica, construído quase que completamente com fotografias - na película só há alguns segundos de imagem em movimento -, no qual o personagem principal, feito prisioneiro numa fictícia terceira guerra mundial, que tornou o mundo inabitável, é escolhido para dormir e sonhar com seu passado, justamente por sua capacidade de recordação (ali, os guardas vigiavam 
até os sonhos). Essas viagens no tempo têm como objetivo buscar fontes de energia para salvar a humanidade condenada, como resultado da guerra, a viver em subterrâneos. Marker entende que metade do tempo do filme que estamos vendo é tela escura. Entre cada fotograma que a película projeta, ocorre um tempo de passagem, preto, imperceptível que só existe no tempo entre imagens, não na película. Mas fundamental para que possamos vê-las.

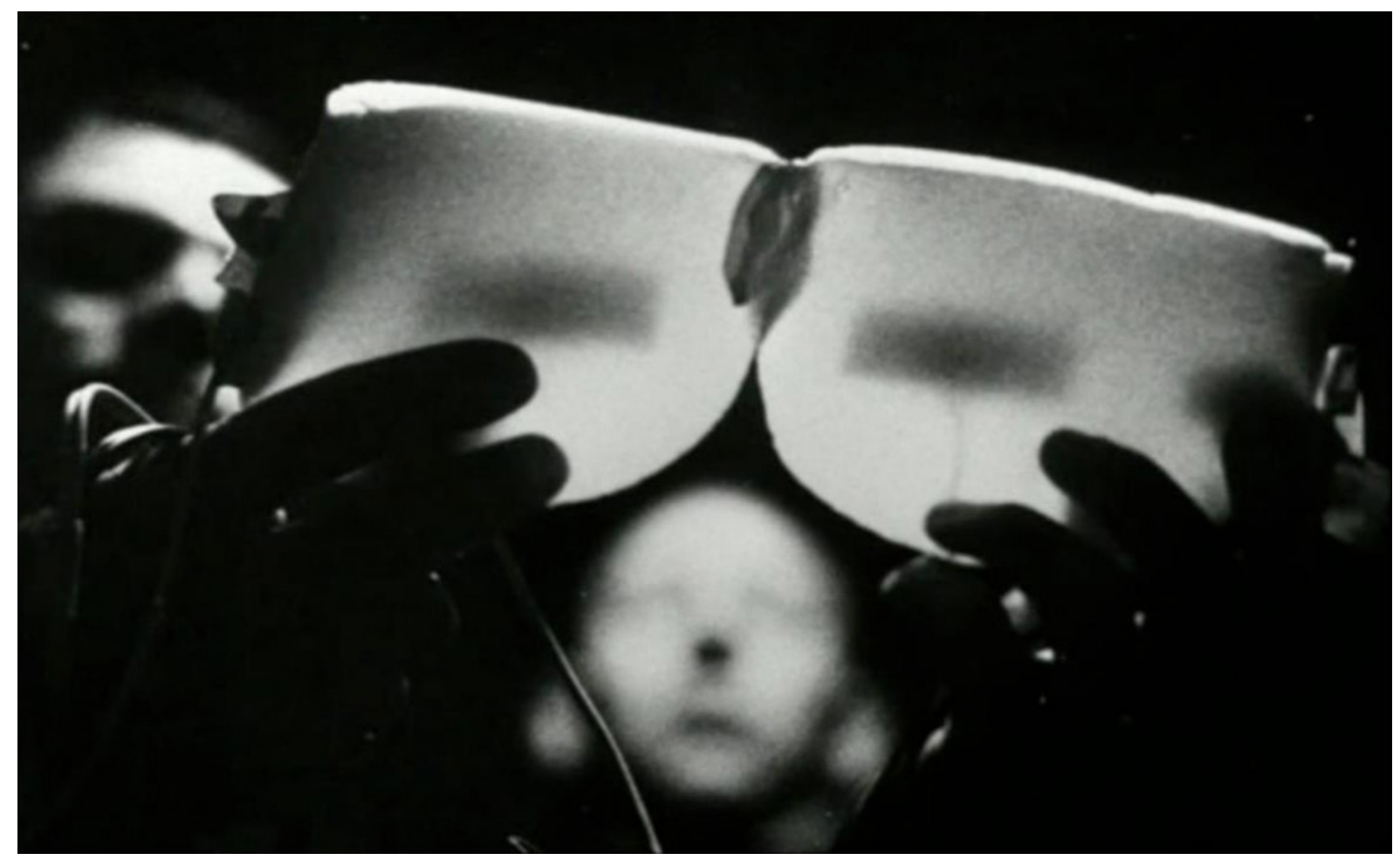

Figura 2. Fotograma do filme La Jetée, de Chris Marker (1962)

A construção do filme, com fotografias e alguns segundos de imagem em movimento, é um comentário sobre o ver e sobre cinema. A moça, que é a recordação mais forte do personagem principal, no meio do filme olha para a câmera e dá uma piscadela. Essa imagem - a única em movimento nos 28 minutos do filme - revela o jogo metalinguístico de Marker sobre o filme, sobre seu entendimento de cinema, ao mesmo tempo em que é um comentário filosófico do diretor sobre o ver. 

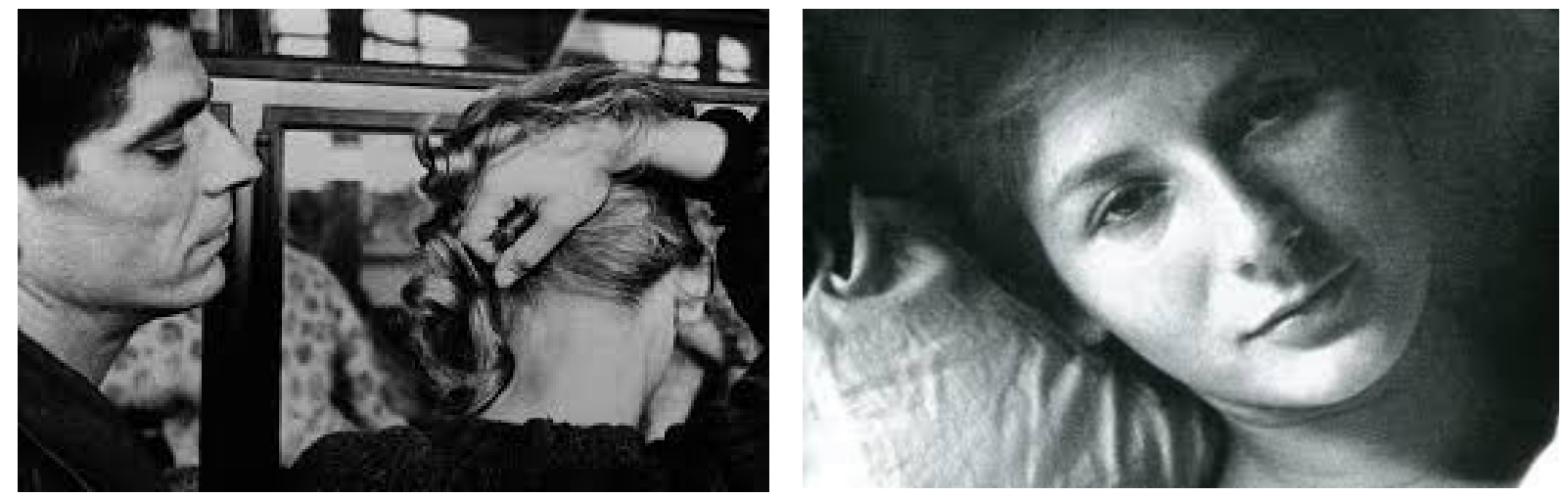

Figuras 3 e 4. Fotogramas do filme La Jetée, de Chris Marker (1962)

Como as piscadelas, que alternam o nosso olhar com ver e não ver, os tempos pretos no filme são a condição da possibilidade de ver. Na projeção, a sequência obedece a um ritmo entre pretos e imagens, assim como as piscadelas obedecem a um ritmo composto com o invisível. Isso corresponde a uma espécie de onda sonora e temporal que Derrida identifica como um tropo suplementar: o ver seria, portanto, como o cego de mãos dadas com o vidente, suplementado pela retórica (ou a retórica como alteridade). Estar com os olhos atentos, como um caçador, não nos garante uma boa visibilidade, porque precisamos piscar para manter os olhos abertos.

Para ver, como o caçador, é preciso estar de frente. Por isso, está pressuposta alguma distância entre o que vê e o que é visto - o distanciamento é condição da visibilidade. No texto "Pensar em não ver", Derrida (2012, p. 63-89) lembra que os olhos humanos veem de frente, veem o horizonte, ou veem na horizontal. O ver de frente antecipa a coisa. No entanto, a coisa mesma sempre escapa, na medida em que nunca podemos ver a totalidade, vemos sempre entre a visibilidade e a cegueira, entre vistas.

Donde ver é muito mais uma questão de crer ver, de pensar ver, de fé, de hipótese de vista. Se a coisa mesma sempre escapa, lidamos com a metaforicidade do "real", uma espécie de "como se" da coisa. Nietzsche dizia que a relação do homem com o mundo é interditada desde o início. Então ele cria uma relação do homem com o mundo, como se o homem tecesse uma rede, uma colmeia sobre o mundo, como se houvesse véus entre o pensamento e a verdade (no nosso caso, entre o pensamento e a coisa, o objeto ou a experiência artística), de modo tal que ver 
fosse como um jogo de descobrimento de véus, onde há sempre um outro véu e mais outro a manter esse distanciamento, esse afastamento como possibilidade de visualidade. Ou, dizendo de outra maneira, a metaforicidade 4 do "real" como condição de visualidade.

Volto agora ao livro Memórias de Cego, O auto-retrato e outras ruínas. Para ver o que está na obscuridade, seria preciso mais que o sentido da visão, seria necessário o tato. Tatear o escuro para enxergar ali o que se dá a ver. Nesse livro Derrida fala da cegueira do artista desenhador. No momento mesmo de desenhar, ainda que o modelo esteja bem à sua frente, ele tem que tirar os olhos do seu referente e desenhar de memória. O momento mesmo do desenho é cego e é ruína na origem. Como se o desenhador pudesse ter olhos na ponta dos dedos, quase tateando a memória para colocar o traço no papel. Esse momento de cegueira não é vivido somente pelo desenhador, mas por quase todo artista. No final do livro, o filósofo conclui que o olho, no fundo, não está destinado a ver. O próprio do olho, ou a essência do olho, é a lágrima, porque é no momento do velamento, do enceguecimento pela água, que se revela a verdade do olho, a cegueira reveladora:

\begin{abstract}
Apenas ele sabe ver isso [voir ça], o homem, que as lágrimas são a essência do olho - e não a visão. A essência do olho é o próprio do homem. Contrariamente ao que se crê saber, o melhor ponto de vista (o ponto de vista [point de vue] terá sido nosso tema) é um ponto de fonte [point de source] e um ponto de água [point d'eau] - vem a ser as lágrimas. A cegueira que abre o olho não é a que entenebrece a vista. A cegueira reveladora, a cegueira apocalíptica, a que revela a própria verdade dos olhos, seria o olhar velado de lágrimas. (Derrida, 2010, p. 130).
\end{abstract}

Mas essa cegueira da qual fala Derrida não é reveladora somente porque a lágrima vela a vista. Ela é porque, no momento do desenho, quando o lápis encosta no papel e é só memória, é ruína. Todavia, não é diante de quem olha, mas é a própria experiência que arruína. E é ruína cheia de espectralidade, carregada de fantasmas, é a visibilidade possível, e, porque plena de espectros, é retórica - a visibilidade mostra-se na reverberação de muitas vozes.

\footnotetext{
$4 \quad$ Na medida em que Nietzsche cria uma relação com o mundo, ele cria a ideia de metaforicidade, que não é a reabilitação da metáfora, e que supõe o afastar-se, o deslocar-se, o desviar-se, no sentido de fazer justiça ao movimento de escapar, ao jogo dos véus.
} 
O ato de memória apresenta-se como a operação do desenho. Quando o olhar do desenhista mergulha no fundo do abismo do papel em branco, esta é a chance da obra. E o que resulta da operação, ou o que retorna no desenho, é o espectro do invisível, uma espécie de incompletude, porque o que vemos é a própria experiência da ruína. Derrida nos diz que ruína é memória, como uma fenda aberta num olho que não nos deixa ver nada, "nada que não se abra, se rompa ou se esburaque" (Derrida, 2010, p. 74).

Fecha os olhos e vê, porque cegueira e clarividência são suplementares. Para ver, mais do que o enfrentamento, é necessária a manha de um olhar oblíquo, um ver sem ver para que surja o evento. Antes que nos vejamos vistos, o olhar do outro nos invade, sem convite. Para olhar o outro sem pudor, é preciso que ele esteja cego e não se veja visto. Só ao cego podemos lançar um olhar despudoradamente contínuo. Mas, sem que o outro nos veja, não o tocamos. É preciso que o outro me veja vendo para tocá-lo. Mas para o que se olha, para o olho ou para o olhar do outro? E, quando vemos entrevendo, quando olhamos para o outro, vemo-lo na cegueira ou na visão? Vemos ou cremos ver?

Perseu, ao enfrentar a Medusa, precisou de um ardil para derrotá-la. Se a olhasse de frente, se a enfrentasse, ele viraria pedra. Então através do reflexo de seu escudo, olhando-a sem olhar, obliquamente, pôde decapitá-la. Mais do que uma hipótese de vista - mais do que crer ver -, o herói grego valeu-se de uma hipótese abocular, isto é, cegado pelo próprio escudo, o que Perseu viu foi um movimento da différance. Sua vitória passou pela conquista do olho pela manha.

Na inelutável modalidade do visível, nos limites do diáfano,

- "se se pode pôr os cinco dedos através, é porque é uma grade, se não uma porta" (Joyce, 1966, p. 41-42).

- "Não sei. É preciso crer. [...]" (Derrida, 2010, p. 132).

\section{Referências}

DERRIDA, Jacques. Pensar em não ver: escritos sobre as artes do visível (19792004). Organização Ginette Michaud, Joana Masó, Javier Bassas. Tradução Marcelo Jacques de Moraes. Florianópolis: Ed. da UFSC, 2012.

. Memórias de cego e outras ruínas; tradução Fernanda Bernardo. Lisboa: Fundação Calouste Gulbenkian, 2010. 
. Le toucher, Jean-Luc Nancy. Paris: Éditions Galilée, 2000.

FERREIRA,Glória; COTRIM, Cecília. Escritos de artistas: anos 60/70. Rio de Janeiro: Jorge Zahar Ed, 2006.

GISNBURG, J. (Org.). A República de Platão. São Paulo: Perspectiva, 2014.

JOYCE, James. Ulisses. Tradução Antonio Houaiss. Rio de Janeiro: Editora Civilização Brasileira, 1966.

RIVERA, Tania. Cinema, imagem e psicanálise. Rio de Janeiro: Jorge Zahar Ed., 2008.

\section{Referências Filmográficas}

LA JETÉE. Direção Chris Marker. Produção: Anatole Dauman. Intérpretes: Jean Négroni, Hélène Chatelain, Davos Hanich e outros. Roteiro: Chris Marker. Música: Trevor Duncan. Paris: Argos Films, Radio-Télévision Française (28 min), black and White. 